\title{
Sensitivity Analysis for Water Vapor Profile Estimation with Infrared: IR Sounder Data Based on Inversion
}

\author{
Kohei Arai ${ }^{1}$ \\ Graduate School of Science and Engineering \\ Saga University \\ Saga City, Japan
}

\begin{abstract}
Sensitivity analysis for water vapor profile estimation with Infrared: IR sounder data based on inversion is carried out. Through simulation study, it is found that influence due to ground surface relative humidity estimation error is greater than that of sea surface temperature estimation error on the water vapor vertical profile retrievals.
\end{abstract}

Keywords- IR sounde; error budget analysis; MODTRAN; air temperature; relative humidity.

\section{INTRODUCTION}

Air-temperature and water vapor profiles are used to be estimated with Infrared Sounder data [1]. One of the problems on retrieving vertical profiles is its retrieving accuracy. In particular, estimation accuracy of air-temperature and water vapor at tropopause ${ }^{1}$ altitude is not good enough because there are gradient changes of air-temperature and water vapor profile in the tropopause so that observed radiance at the specific channels are not changed for the altitude.

In order to estimate air-temperature and water vapor, least square based method is typically used. In the process, Root Mean Square: RMS difference between observed radiance and calculated radiance with the designated physical parameters are minimized. Then the designated physical parameters including air-temperature and water vapor at the minimum RMS difference are solutions.

Typically, Newton-Raphson method ${ }^{2}$ which gives one of local minima is used for minimization of RMS difference. Newton-Raphson needs first and second order derivatives, Jacobean and Hessian at around the current solution. It is not easy to formularize these derivatives analytically. The proposed method is based on Levenberg Marquardt: LM of non-linear least square method ${ }^{3}$. It uses numerically calculated first and second order derivatives instead of analytical based derivatives. Namely, these derivatives can be calculated with radiative transfer model based radiance calculations. At around the current solution in the solution space, directional derivatives are calculated with the radiative transfer model.
The proposed method is validated for air-temperature and water vapor profile retrievals with Infrared: IR sounder ${ }^{4}$ data derived from AQUA/AIRS [2]-[7]. A comparison of retrieving accuracy between Newton-Raphson method and the proposed method based on LM method [8] is made in order to demonstrate an effectiveness of the proposed method in terms of estimation accuracy in particular for the altitude of tropopause [9]. Global Data Assimilation System: GDAS ${ }^{5}$ data of assimilation model derived 1 degree mesh data is used as truth data of air-temperature and water vapor profiles. The experimental data show that the proposed method is superior to the conventional Newton-Raphson method.

Atmospheric sounding can be improved by using the high spectral resolution of sounder, such as AIRS, IASI, instead of HIRS, TOVS used in the past three and half decades[10]-[13]. Their sensors have large number of channels, and have large amount of atmospheric sounding information in the measurement data. But for the retrieval of air temperature profile, it is not practical nor an advantage to use all spectral points. Therefore it is important for this work to eliminate those channels whose information does not add to the final retrieval accuracy and even before for the sake of efficiency, those channels potentially contaminated by solar radiation or significantly affected by other gases (not required for temperature profiling.

Sensitivity analysis of water vapor profile retrieval against surface relative humidity and sea surface temperature is carried out. Multi channels utilized retrieval method is assumed for water vapor profile estimation. Then influences due to surface relative humidity and sea surface temperature on water vapor profile retrieval accuracy are investigated.

The following section describes background of the research as well as assumptions for sensitivity analysis followed by detailed method for sensitivity analysis. Secondly, experiments are described with simulation results followed by conclusion and some discussions.

\footnotetext{
${ }^{4}$ http://en.wikipedia.org/wiki/Atmospheric_Infrared_Sounder

${ }^{5}$ http://www.mmm.ucar.edu/mm5/mm5v3/data/gdas.html
}

\footnotetext{
${ }^{1}$ http://en.wikipedia.org/wiki/Tropopause

${ }^{2}$ http://en.wikipedia.org/wiki/Newton's_method

http://en.wikipedia.org/wiki/Levenberg\%E2\%80\%93Marquardt_algorithm
} 


\section{RESEARCH BACKGROUND AND METHIOD FOR SENSITIVITY ANALYSIS}

\section{A. Infrared: IR Sounder}

Sounder instruments on Earth observation satellite are for ozone, water vapor and air temperature vertical profile retrievals with very narrow bandwidth of wavelength channels which measure radiation from the Earth. There are many absorption bands due to atmospheric molecule in infrared and microwave wavelength regions. Atmospheric optical depths are varied with altitude above sea level. Therefore, vertical profile of density of the atmospheric molecules can be estimated results in ozone, water vapor, air temperature profiles can be retrieved.

Table 1 shows major purposes, absorption molecules, and the most appropriate wavelength or frequency regions.

TABLE I. MAJOR PURPOSES, ABSORPTION MOLECULES, AND THE MOST APPROPRIATE WAVELENGTH OR FREQUENCY REGIONS FOR SOUNDER

\begin{tabular}{|l|l|l|l|}
\hline $\begin{array}{l}\text { Wavelength_ } \\
\text { Region }\end{array}$ & $\begin{array}{l}\text { Wavelength } \\
\text { _Frequency }\end{array}$ & $\begin{array}{l}\text { Absorption_ } \\
\text { Molecule }\end{array}$ & Major_Purpose \\
\hline Infrared & $6.3 \mathrm{um}$ & $\mathrm{H} 2 \mathrm{O}$ & Water_vapor \\
\hline Infrared & $9.6 \mathrm{um}$ & $\mathrm{O} 3$ & Ozone \\
\hline Infrared & $15 \mathrm{um}$ & $\mathrm{CO} 2$ & $\begin{array}{l}\text { Air } \\
\text { Temperature }\end{array}$ \\
\hline Microwave & $22.235 \mathrm{GHz}$ & $\mathrm{H} 2 \mathrm{O}$ & Water_vapor \\
\hline Microwave & $60 \mathrm{GHz}$ & $\mathrm{O} 2$ & $\begin{array}{l}\text { Air } \\
\text { Temperature }\end{array}$ \\
\hline
\end{tabular}

\section{B. Profile Retrieval Method}

IR sounder data derived radiance, $R_{0 i}$ and estimated radiance, $R_{\mathrm{i}}$ based on atmospheric model with the parameters of air-temperature and relative humidity.

$$
S=\sum_{i=0}^{n} R_{i}-R_{0 \mathrm{i}}{ }^{2}
$$

Thus the geophysical parameter at when the difference of radiance reaches to the minimum is estimated. Widely used and accurate enough atmospheric software code of MODTRAN $^{6}$ is used in the proposed method. Solution update equation of Newton-Raphson method is expressed by equation (2).

$$
\mathrm{X}_{\mathrm{n}+1}=\mathrm{X}_{\mathrm{n}}-\mathrm{H}^{-1} \mathrm{~J}\left(\mathrm{x}_{\mathrm{n}}\right)
$$

where $H$ denotes Hessian matrix ${ }^{7}$ which consists of second order derivatives (residual square error, $S$ which is represented by equation (1) by geophysical parameter, air-temperature and relative humidity). Also $J$ denotes Jacobean ${ }^{8}$ which consists of the first derivative of vectors ( $S$ by geophysical parameters, $x$ ).
On the other hand, solution update equation is expressed by equation (3).

$$
\mathrm{X}_{\mathrm{n}+1}=\mathrm{X}_{\mathrm{n}}+\left(\mathrm{J}^{\mathrm{T}} \mathrm{J}+\mathrm{I}\right)^{-1} \mathrm{~J}^{\mathrm{T}}\left(\mathrm{R}_{\mathrm{i}}-\mathrm{R}_{0 \mathrm{i}}\right)
$$

The first derivative is represented by equation (4) while the second order derivative is expressed by equation (5), respectively.

$$
\frac{\partial S}{\partial x_{i}}=-2 \sum_{k=1}^{n} R_{k}-R_{0 \mathrm{k}} \frac{\partial R_{0 \mathrm{k}}}{\partial x_{i}}[
$$

$$
\frac{\partial^{2} S}{\partial x_{i} \partial x_{j}}=2 \sum_{k=1}^{n}\left[\frac{\partial R_{0 \mathrm{k}}}{\partial x_{i}} * \frac{\partial R_{0 \mathrm{k}}}{\partial x_{j}}-\left[R_{k}-R_{0 \mathrm{k}}\left[\frac{\partial^{2} R_{0 \mathrm{k}}}{\partial x_{i} \partial x_{j}}\right]\right.\right.
$$

(5)

On the other hand, the first and second order derivatives of $R$ with $x$ are expressed by equation (6) and (7), respectively.

$$
\begin{aligned}
& \frac{\partial R_{0 \mathrm{k}}}{\partial x_{i}} \leftarrow \text { MODTRAN } \\
& \frac{\partial^{2} R_{0 \mathrm{k}}}{\partial x_{i} \partial x_{j}} \leftarrow \frac{\partial R_{0 \mathrm{k}}}{\partial x_{i}} * \frac{\partial R_{0 \mathrm{k}}}{\partial x_{j}}
\end{aligned}
$$

In the proposed method, these derivatives are calculated numerically. $2 \%$ changes of relative humidity is taken into account for calculation of derivative $R$ and $S$ while $0.5 \mathrm{~K}$ changes of air-temperature is also considered for calculation of derivative of $R$ and $S$. Thus the geophysical parameter at when the difference of radiance reaches to the minimum is estimated.

\section{Weighting Function}

Based on radiative transfer model, upwelling radiance from the atmosphere is greater than ground surface radiance in accordance with absorption molecule density in the case that the atmosphere contains a plenty of absorption molecules.

Weighting function which represents contributions to upwelling radiance at all the altitudes can be determined by optical depth. Namely,

$$
\begin{aligned}
& K(z)=\int_{0}^{\propto} \frac{\partial e^{-\tau(p, \rho)}}{\partial p} d p \\
& \operatorname{tr}(z)=e^{\left(-\int_{z}^{z_{\alpha}} \rho k_{v} d z\right)}=e^{-\tau}
\end{aligned}
$$

where $\mathrm{K}$ denotes weighting function, $\operatorname{tr}$ denotes transparency, $\tau$ denotes optical depth, and $\mathrm{p}$ denotes atmospheric pressure while $\mathrm{z}$ denotes altitude. Also $\rho$ denotes molecule density. For instance, weighting function for 6.3, 7.3, 7.5 um wavelength of $\mathrm{H} 2 \mathrm{O}$ absorption channels are shown in Figure 1.

\footnotetext{
${ }^{6}$ http://en.wikipedia.org/wiki/MODTRAN

${ }^{7} \mathrm{http}$ ://en.wikipedia.org/wiki/Hessian_matrix

${ }^{8}$ http://en.wikipedia.org/wiki/Jacobian_matrix_and_determinant
} 


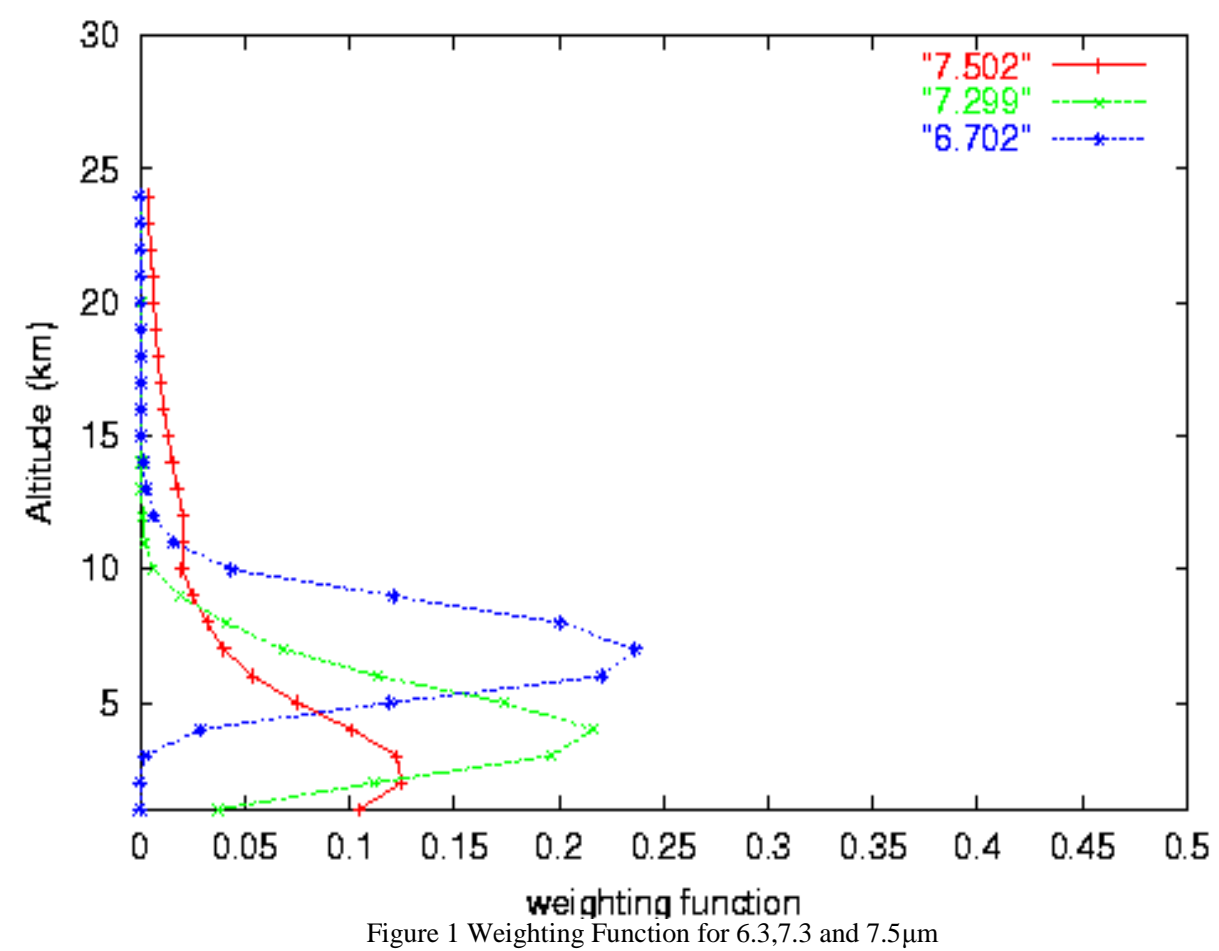

\section{Method for Sensitivity Analysis}

Assuming MODTRAN is truth, water vapor profile retrieval error is evaluated by which some errors are added to surface air temperature and relative humidity. Then it is possible to clarify relations between water vapor profile retrieval error caused by the errors on the surface air temperature and relative humidity. In the process, steepest descending method of non-linear optimization method for single variable is used for determination of optimum solution of water vapor profile. Equation (9) and (10) shows steepest descending method.

$\left(I_{\text {toa }}-\stackrel{\Lambda}{I}\right)^{2} \leq \varepsilon$.

$R H^{n+1}=R H^{n}+\lambda \frac{d I^{n}}{d R H^{n}}$

Thus the retrieval error can be evaluated.

\section{EXPERIMENTS}

\section{A. Experimantal Parameters}

All the parameters required for experiments is listed in the Table 2. Residual errors of water vapor estimation for surface temperature and relative humidity are shown in Figure 2 and 3, respectively. On the other hands, retrieved water vapor profile is shown in Figure 4. \pm 5 and $\pm 10(\%)$ of errors are added to the default relative humidity in this case.

TABLE II. PARAMETERS FOR EXPERIMENTS

\begin{tabular}{|l|l|}
\hline Atmospheric_Model & Mid.Latitude_Summer \\
\hline Wavelength & $6.7,7.3,7.5 \mathrm{um}$ \\
\hline Default_Relative_Humidity & $0 \%, \pm 10 \%, \pm 30 \%$, \\
\hline Default_Air_Temperature & $0, \pm 1, \pm 3 \mathrm{~K}$ \\
\hline Altitude_at_Top_of_Atmosphere & $100 \mathrm{~km}$ \\
\hline
\end{tabular}




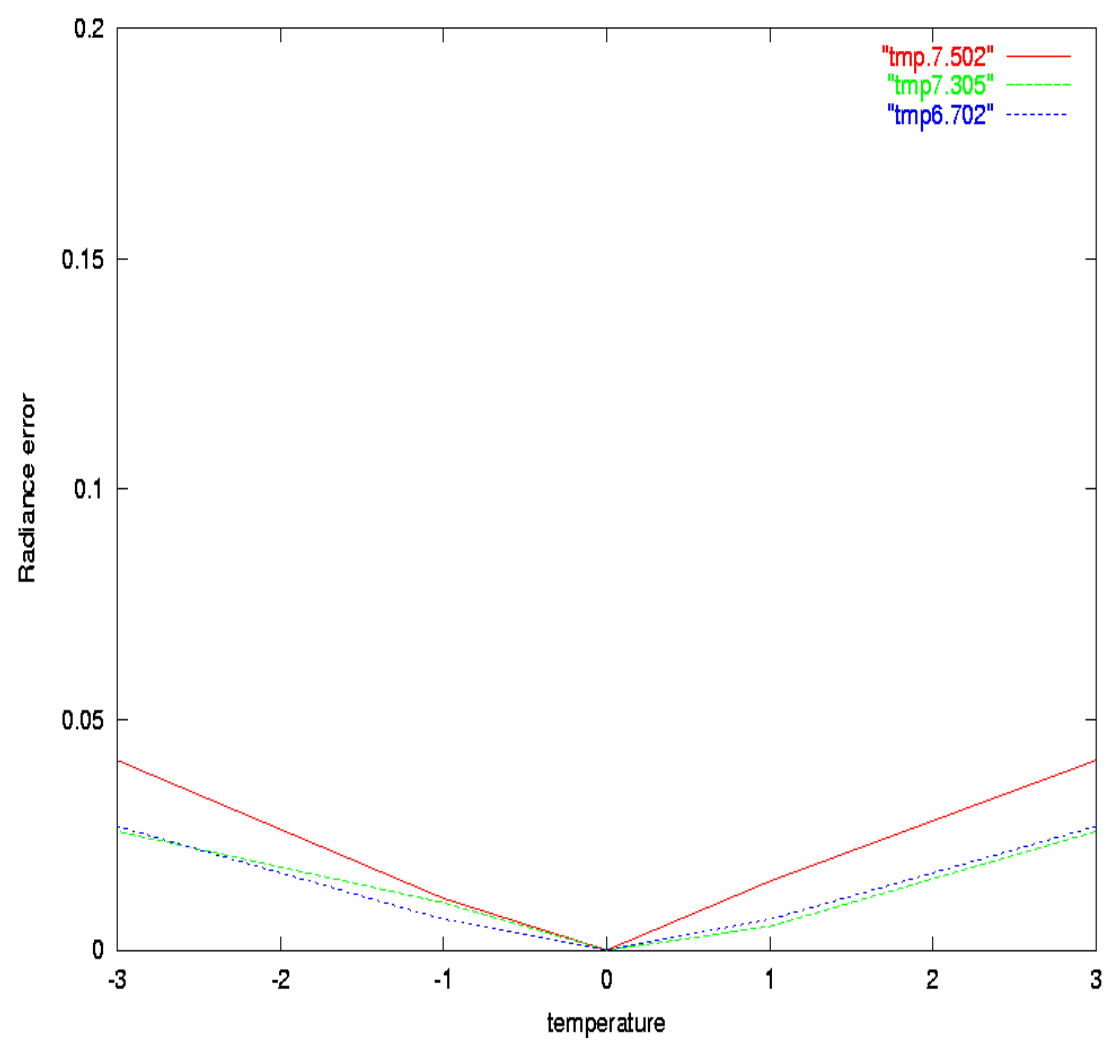

Figure 2 Sensitivity of surface air temperature

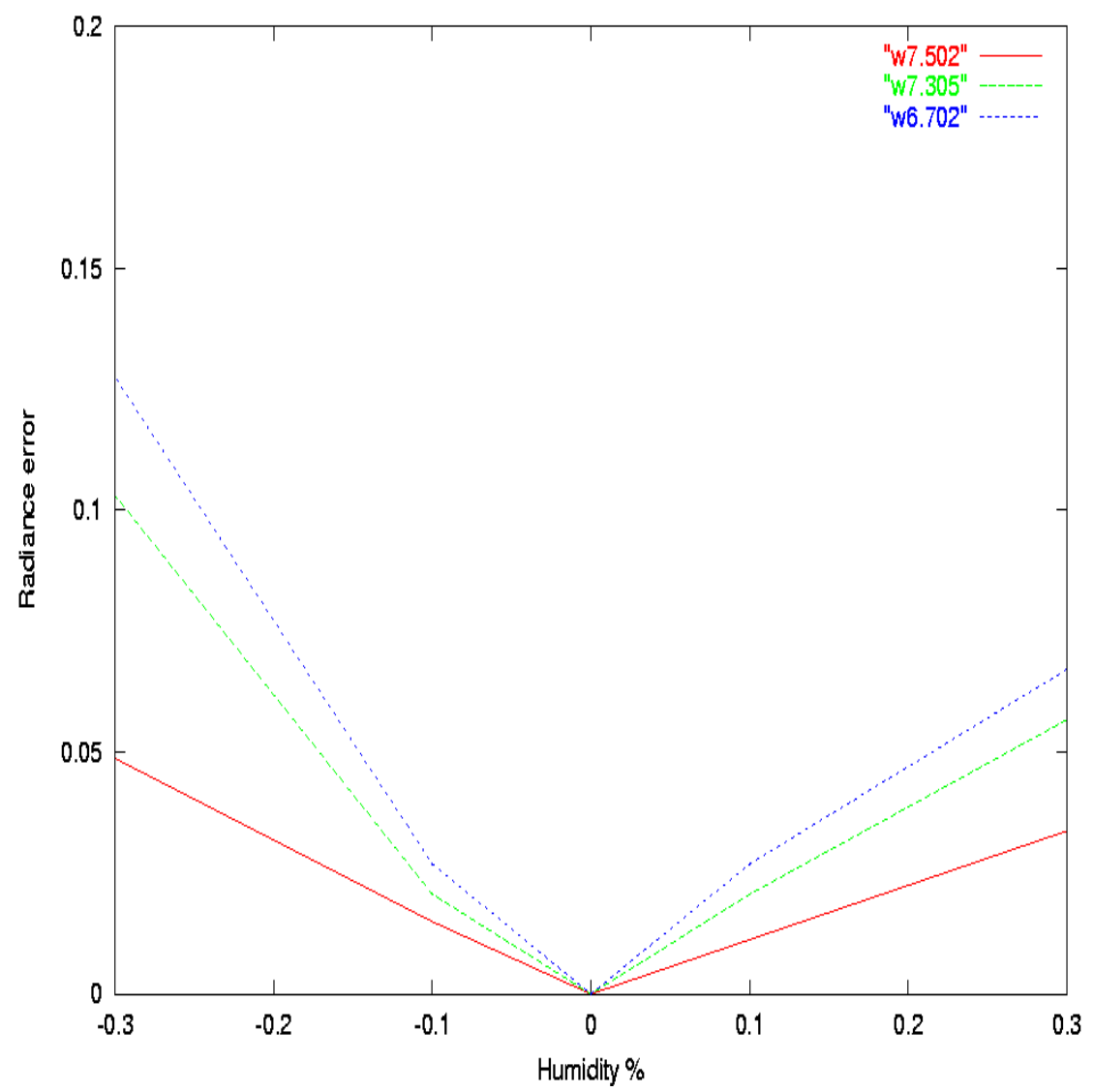

Figure 3 Sensitivity of relative humidity 


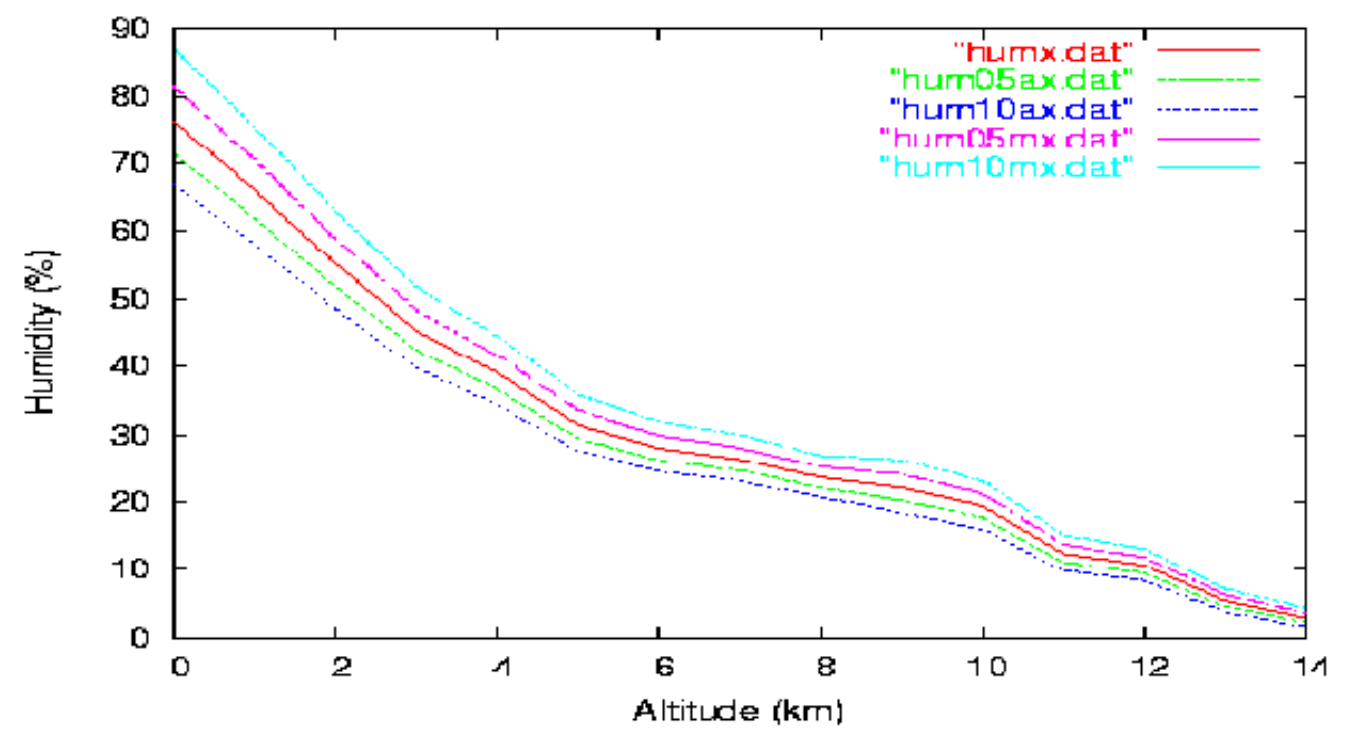

Figure 4 Estimated water vapor profile

\section{B. Summerized Experiemntal Results}

Through the comparison between Figure 2 and 3, it is found that influence due to error on the relative humidity is greater than that due to surface air temperature. It is reasonable that relative humidity is closely linked to water vapor profile rather than surface air temperature.

Estimated water vapor profile shows also reasonable. In the troposphere, humidity is decreasing smoothly. At around tropopause, there is sharp drop of humidity. This is because that troposphere and stratosphere are interacted weakly each other. Estimated humidity profile shows that $\pm 10 \%$ of error which is added to the default humidity is going to be small and greater depending on the altitude. Also it shows a difficulty on water vapor profile retrieval at around tropopause.

\section{CONCLUSION}

Sensitivity analysis for water vapor profile estimation with Infrared: IR sounder data based on inversion is carried out. Through simulation study, it is found that influence due to ground surface relative humidity estimation error is greater than that of sea surface temperature estimation error on the water vapor vertical profile retrievals.

It is found that influence due to error on the relative humidity is greater than that due to surface air temperature. It is reasonable that relative humidity is closely linked to water vapor profile rather than surface air temperature.

\section{ACKNOWLEDGMENT}

The author would like to thank Mr. Wang King and Dr. Xing Ming Liang, for their effort to experiments.

\section{REFERENCES}

[1] Kohei Arai, Lecture Note on Remote Sensing, Morikita-Shuppan publishing Co. Ltd, 2004.
[2] NASA/JPL, "AIRS Overview". NASA/JPL. http://airs.jpl.nasa.gov/overview/overview/.

[3] NASA "Aqua and the A-Train". NASA. http://www.nasa.gov/mission_pages/aqua/.

[4] NASA/GSFC "NASA Goddard Earth Sciences Data and Information Services Center". NASA/GSFC. http://disc.gsfc.nasa.gov/AIRS/data_products.shtml.

[5] NASA/JPL "How AIRS Works". NASA/JPL. http://airs.jpl.nasa.gov/technology/how_AIRS_works.

[6] NASA/JPL "NASA/NOAA Announce Major Weather Forecasting Advancement". http://jpl.nasa.gov/news/news.cfm?release=2005-137.

[7] NASA/JPL "New NASA AIRS Data to Aid Weather, Climate Research". NASA/JPL. http://www.jpl.nasa.gov/news/features.cfm?feature=1424.

[8] Kohei Arai and Naohisa Nakamizo, Water vapor and air-temperature profile estimation with AIRS data based on Levenberg -Marquardt, Abstract of the 50th COSPAR(Committee on Space Research/ICSU) Congress, A 3.1-0086-08,995, Montreal, Canada, July, 2008

[9] Kohei Arai and XingMing Liang, sensitivity analysis for air temperature profile estimation method around the tropopause using simulated AQUA/AIRS data, Advances in Space Research, 43, 3, 845-851, 2009.

[10] Jeffrey, A.L., Elisabeth, W., and Gottfried, K., Temperature and humidity retrieval from simulated Infrared Atmospheric Sounding Interferometer(IASI) measurements, J. Geop. Res., 107, 1-11, 2002.

[11] Rodgers, C.D., Information content and optimization of high spectral resolution measurements. In Optical Spectroscopic Techniques and Instrumentation for Atmospheric and Space Research II, vol. 2830, pp. 136-147, Int. Soc. For Optical Eng., Bellingham, Wash.,1996.

[12] Rodgers, C.D., Inverse method for atmospheres: theory and practice, World Sci., Singapore, 2000.

[13] Liou, K.N., An introduction to atmospheric radiation. Elsevier Science, USA, 2002.

\section{AUTHORS PROFILE}

Kohei Arai, He received BS, MS and PhD degrees in 1972, 1974 and 1982, respectively. He was with The Institute for Industrial Science and Technology of the University of Tokyo from April 1974 to December 1978 also was with National Space Development Agency of Japan from January, 1979 to March, 1990. During from 1985 to 1987, he was with Canada Centre for Remote Sensing as a Post Doctoral Fellow of National Science and Engineering Research Council of Canada. He moved to Saga University as a Professor in 
Department of Information Science on April 1990. He was a councilor for the Aeronautics and Space related to the Technology Committee of the Ministry of Science and Technology during from 1998 to 2000 . He was a councilor of Saga University for 2002 and 2003. He also was an executive councilor for the Remote Sensing Society of Japan for 2003 to 2005. He is an Adjunct Professor of University of Arizona, USA since 1998. He also is Vice Chairman of the Commission "A" of ICSU/COSPAR since 2008. He wrote 30 books and published 322 journal papers. 